\title{
Research Methodology in Kurdish Studies
}

\author{
Interactions between Fieldwork, Epistemology and Theory
}

\author{
Mehmet Orhan
}

\begin{abstract}
Kurdish studies are generally defined and conducted according to a topic or geographic location, namely, within the Middle East. Research procedures used to handle different issues as well as develop concepts and hypotheses have become important, since most of the current theories lack practical approaches when conducting studies on the Kurds. Relying on specific examples, published sources as well as the author's personal fieldwork and insights, the article establishes a critique of bias, problems and solutions in research goals and methodologies in the field of Kurdish studies. The article underlines the importance of problemoriented research, notably addressing the questions who, where, when, how and why. Furthermore, it shows the way in which the personality of the researcher, as well as the fluctuations and constraints encountered during the fieldwork, influence the methodology. Finally, it emphasises the practical and theoretical challenges dealt with by the researcher due to the political aspect of the Kurdish question, which encompasses orientalist, imperial, or national interests.
\end{abstract}

Keywords: epistemology, fieldwork, Kurds, methodology, Middle East, social sciences, theory

Kurds live in a land where imperialist, economic and interethnic struggles overlap. This geography is fragmented along tribal, religious (Muslim vs. Christian and Sunni vs. Shia, etc.) and political affiliations, but relative cultural 'unity', ${ }^{1}$ despite the variations between the Kurdish populations, provide the Kurds with a specific identity. This has created a unique Kurdish geography with a distinct social dynamic in comparison with other regions in the Middle East.

The nationalist movements during the Ottoman period in the nineteenth and twentieth centuries impacted the various cultures and populations within 
the empire very differently. Bulgarians, Greeks, Arabs, Armenians and Kurds did not experience this process in the same manner, as religion, geography and power relations with the Ottoman Empire determined how they reacted to nationalism and modernist trends. While the Kurds sparked both the political and scientific interest of scholars, diplomats and travelers, the collective national movements for Kurds developed later than for other ethnic groups. Social and linguistic differences have existed for centuries between the Kurds and neighbouring communities and cultures. Nonetheless, individual or collective feelings of difference, whether linguistic, religious or social, do not necessarily translate into political nationalist organisations. The creation of nationalist, separatist or radical organizations often depends on the formation of a marginalised 'elite' ${ }^{2}$ group that is able to build a political body seeking autonomy, revolution or any change in the political and social system (Skocpol 1994). This radicalised leadership can be a tribal chief, sheikh, teacher, student or proletarian who is able to communicate their ideas with the society and construct a culturally and politically distinct community via ideological movements. The political mobilisation of Kurdish communities through ideological movements and their radicalised leaderships occurred most frequently during the Cold War period. Although not entirely separate in their goals and dynamics, different mobilisations in various national contexts (Iraq, Turkey, Iran, Syria) $)^{3}$ created greater interest in the Kurdish question.

We can thus consider the increase of scientific interest in the Kurds partially as the outcome of their political mobilisations, as well as their geostrategic and historical importance in the Middle East. The Kurds are increasingly being studied by a range of researchers coming from different countries and cultures, creating a number of methodological and theoretical problems that need to be addressed. Addressing this issue is particularly relevant because of the twofold gap it creates, namely, the gap between theoretical studies and methodological studies, as well as the gap between social, cultural and political studies and area studies. Indeed, many of the essential social and political science works, which are foundational to any subsequent research on the Kurds or the Middle East, fail to detail and develop their methodology. Substantial findings tend to omit the research methods that have enabled these studies. Several of the most established works in anthropology and sociology have no methodological section or clarification. For example, Max Weber is one of the most methodologically rigorous writers in social sciences, in addition to his theoretical innovations like the different types of domination and legitimation. Weber developed a method to build typologies that attached importance to empirical research while discussing scientific objectivity and ethical neutrality (Weber 1949, 1971; see also Lazarsfeld and Oberschall 1965). However, we still ignore the detailed research techniques on the various ways to observe different types of domination and legitimation in societies, likely resulting from the separate discussion of theory and observation (see Shil's foreword to Weber 1949). This problem has certainly lessened due to the development of methodological 
and fieldwork techniques; nevertheless, it still persists in more contemporary works: Ernest Gellner's (1984) work on nationalism explains nationalism, but does not necessarily provide techniques to methodologically study nationalism, among the Kurds or any other society. Similarly, Kimberle Crenshaw's (1991) important theory of intersectionality is well defined, but lacks indications for its observation. Such a lack of theoretical works makes the methodological observation and application in different societies difficult, including in Kurdish communities.

The problem is much more serious in area studies like Kurdish or Middle Eastern studies. This lack may be the result of scholars seeing methodology as a subfield of social sciences, political challenges and obstacles when conducting field or archive research, or that they may have no method beyond the use of secondary sources. However, methodology as well as theory are integral parts of any social science study that deserve particular attention in the making of research.

\section{Research Problem, Goals and Fieldwork Methodology}

People who work on the Kurds are usually identified as being specialists in Kurdish studies. According to the social sciences' definition, this description does not mean much because it provides little information about this broad topic, creating the need for a number of questions and specified categories to delimit the subject matter. Kurdish studies undoubtedly has historically important works like Sharaf Khân Bidlîsîs Sharafnama ([1597] 1969), or İsmet Şerif Vanlı's forgotten books on the Kurds in Syria (e.g. Le problème kurde en Syrie, 1968), but most of the contemporary works approach the topic from a generalist perspective; thus, this necessitates more focused research and works. Scholars are indeed supposed to study social, political and cultural issues such as political violence, tribe, nationalism, religion, social movements, gender, divorce or dengbêj (a traditional Kurdish folk singer and storyteller). To be sure, one will conduct more fruitful research if he or she has well-rounded knowledge of the society in question. One can study particular research problems such as: What is the effect of political socialisation on violence? How does gender intersect with social class to result in violence? Why did dengbêj tradition become a means of collective and self-expression among the Kurds?

It is thus essential to understand the basis of the Kurdish society, history and culture in an exhaustive way, but nonetheless within the context of specific research questions and topics. The research question is the basic guideline that drives the content of a text on the basis of observations and their interpretation via hypotheses and theories. ${ }^{4}$

There is a dialectical relationship between the research question, method and empirical observations. If we aim to examine how Kurds became 
nationalist in a gradual manner, a longue durée ${ }^{5}$ approach, in a particular place (village, district or town), we can then conduct oral history interviews with people belonging to different generations and/or use historical texts to study different social and historical processes. Usually, the researcher will ask the following question: Is what I observed related to what I want to explain? Such a question is especially pertinent in Kurdish studies because of the relative difficulty of gathering empirical evidence. It is essential in determining whether the sampling is adequate, random or irrelevant.

Erdal Gezik (2013), who studies Alevism among Kurds, provides similar observations while questioning the appropriateness of sources despite the difficulty of gathering sufficient knowledge. His research can be used to support my argument about the longue durée approach, the necessity to conduct interviews with people of various generations, and the use of historical texts. Indeed, he argues that the secularising laws of republican Turkey, urbanisation and immigration almost abolished traditional seyyid ${ }^{6}$ organisations, resulting in younger generations forgetting the genealogy of religious leadership to which their families and tribes belong to. Consequently, he conducts oral history interviews with older generations and uses historical texts to determine the genealogy of seyyid organisations in the Dersim region. The author also adds that in order to investigate this topic, he had to conduct fieldwork in Dersim because this particular information is unique to people from this province. Gezik's research establishes that without awareness of such temporal and spatial patterns during fieldwork, a random sampling could create problems in research outcomes.

While finding relevant research problems and sampling are crucial, unless we understand the way in which they fit with fieldwork methodologically, research outcomes may be biased. For example, the research question should not be confused with questions that are asked during the fieldwork. Questions in the field are different in nature, depending on the ways, limitations, possibilities and methods of observation. These can be semistructured or unstructured interviews and participant and non-participant observations. The researcher, when conducting fieldwork, usually does not need to ask questions in participant observations. In open-ended discussions, spontaneous questions arise without preparation. Undoubtedly, questions asked in the field relate to the research problem, but they should be generally more practical and not interrogative, since they aim to collect data.

Using semi- or unstructured questions, which are not too interrogative, is ideal in qualitative field methods. They are incredibly insightful when researching very political issues like the Kurdish conflict for several reasons. First of all, direct and interrogative questions rarely lead to open-ended discussions. In the Kurdish context specifically, the topic can be too politically charged, for example, when assessing the participation of people in street insurgencies. It can also deal with social issues that occur in sensitive settings, like 'honour killings'. Such settings are not necessarily political, but are always socially 
closed milieus, where people may not be willing to talk about taboo topics that concern intimacy, sexuality or secrecy. Unstructured questions can diminish the taboo nature of the topic that constitutes structural barriers to obtaining knowledge (Hudson and Okhuysen 2014). Second, questions determine the researcher's position, which ideally should be objective. Third, if questions are open ended, they can request without necessarily constraining people to talk, solving certain ethical problems tied to this type of research. The fieldworker is not a judge and does not have the right to ask the questions that people do not want to answer. Fourth, they recognise the fluidity and complexity of the topic. A priori, the researcher does not know everything about the topic in question, and these types of questions can provide the possibility to talk about unplanned persons, events and questions (Orhan 2015).

Consequently, the methodology of interviews is crucial to effective and ethical fieldwork, particularly concerning sensitive issues. For example, practical questions, such as the ones I asked during my interviews, were necessary to understand the Kurdish conflict during the Iraqi and Syrian civil wars. These questions included: Did you bury the corpses when people were killed in Kobanî war $(2014)^{7}$ or did the bodies stay day and night in the street? Did you respond in Kurdish or in Arabic when you were captured by ISIL militants? What kind of expressions were they using when speaking with you?

Certain types of responses are indicative of dynamics that go beyond the answers themselves. A narrative that includes the account 'We just protested and shouted anti-regime slogans' implies that the Kurds in Kobanî were in the logic of protest rather than armed rebellion when the protest in Deraa, Syria, began in 2011. When people recount the story by saying 'The bodies were left in the street for several days', it shows the importance of survival above traditional rituals during war. An open-ended discussion over the question of language reveals a dynamic of identity, symbolised by specific vocabulary and dialects.

The above information having been derived from an interview with a Kurd from Kobanî in Europe, it is important to acknowledge the external factors that can influence fieldwork. When interviews are conducted in a Kurdish village or town, the setting provides more ethnographic features. Studying specific dynamics in their original contexts versus in a secondary location leads to different perspectives and information collected. The first type of research is embedded in the situation being studied, accessing information only available locally, while the other may enable access to people and information unavailable in dangerous settings.

But what happens if the semistructured or open-ended questions fail to lead to a detailed account of the issue in question? There is certainly a possibility that the interviewee responds to an open-ended question without detail or in a more concise manner than desired. In this case, a second intermediate question such as 'Can you tell me more about that?' (Edwards and Holland 2013: 73) is a way to push the discussion further. 
It is also possible that some interviewees focus on a short space of time, depending on their lived experiences. As interviews can bring up traumatic situations that occurred during war, traumatised individuals are sometimes fixated on the time of the traumatic event (Freud 1920: 236-239). Therefore, the memory might be extremely grounded in a specific place and moment.

Various constraints or obstacles may lead the researcher to use different methods at the same time during fieldwork. If interviews aim to reconstruct case-specific histories or understand complicated local dynamics, they can be completed by supplementary material (local journals, archives, historical books, etc.). This is particularly relevant when the fieldworker does not have the opportunity to conduct interviews with a large variety of people belonging to various age groups, conflict groups and social classes. This method can be referred to as a sort of mixed method using both interviews and textual analysis. The use of mixed methods is not merely due to these specific constraints, but can also be a strategic approach when the required information is not found in a single source.

In addition to the aforementioned factors that one must consider when conducting field research on the Kurds, there are also personal factors related to the researcher that shape the fieldwork. These factors are highly personalised and variable according to the characteristics of the researcher, the population being studied and the timing of the research. As a result, it is difficult to establish fixed methodological rules that are universally accepted. The emphasis on personal qualities implies that ethnographic fieldwork methods are an indeterminate method of knowledge acquisition (Atkinson et al. 2001: 4). This is perhaps why methodological texts rarely discuss individual factors, except for a few written by Marie Elaine Hegland and Erika Friedl. These scholars (2004: 571) argue that despite few standardised principles of ethnographic methodology, individual characteristics and identity of the field researcher influence the way in which one conducts research, resulting in a diverse array of fieldwork styles. My personal experiences can be used to show how the style of fieldwork (interactional patterns and discussions with people) depend, in large part, on the personality and assumptions of the researcher. I was born in a village in a Kurdish province (Adiyaman) of Turkey, and studied at the university in Ankara before pursuing my higher studies in France. I was trained in human and social sciences, which provided me with an interdisciplinary approach to my research topics. During my master's studies in political science and sociology (2004-2006) and doctoral research (2006-2012), I did several fieldwork trips to study the Kurdish conflict and political violence in the Kurdish region of Turkey. Having lived in the Kurdish region and having prior knowledge about the conflict were advantageous. Nonetheless, I noticed that my personal assumptions and characteristics mattered much more than I estimated. While this personal observation underlines the relevance of questioning the advantages and disadvantages of being connected to the community under study, discussions about being an insider or outsider should not categorise the 
researcher by eliminating individual characteristics and experiences. Indeed, the image of an alienated or non-alienated researcher to a population can be of crucial importance to his or her acceptance by the community under study.

During fieldwork, I usually feel that my research occurs in an authentic manner and that I am perceived as real rather than as an alienating and fake image of the research and researcher. There are two reasons that confirm my assumptions. First, the people with whom I speak want to speak with and see me more than I initially thought. Second, I have studied other communities like Arabs, Turks, Syrian and Iraqi Yazidis, or Christians during my different fieldwork trips, all of whom gave me the same impression as the Kurds. Fieldwork methods interact with the personality of the researcher, giving rise to a personalised style of fieldwork. As the topic of this article deals with Kurdish studies, I will offer an example regarding Kurdish studies.

I went to Antep in 2018, a Kurdish province situated in the southeast of Turkey near Syria. I was told about a family there who had escaped the war in Aleppo and taken shelter in Antep. The family reportedly had three members, a man and his father and mother, currently living in a small corner of the basement of an apartment in Antep. I learned the history of this man, who was a prominent doctor living with his wife and children in Syria. An air strike targeted their home, killing his wife and children. The doctor consequently lost his mind and was exiled with his father and mother to Antep, where they live in poor conditions. People told me that he refuses to wear shoes, wandering with bare feet in the streets during the day. When I was told this tragic story and asked to talk with this family, I thought of visiting them. At the same time, I asked myself what I could possibly speak about with a man who had lost his mind and how he could report his past to me. Indeed, once a man becomes insane, time is not essential anymore but anecdotal, meaning that his relationships to this world have entirely changed, as there exists nothing than mere eternity for himself (Laing 1969: 92). I compared this case with another Syrian family who took shelter in a village in Adıyaman, making a living as harvest workers. In 2015, I did not have time to speak with them about war, and when I asked about them two years later, someone told me that it was too late to speak with them. They had gone back to Syria to celebrate an Islamic feast and some of them were probably killed in an air strike. They were likely presumed to be ISIL militants even though they did not have any political affiliations. Reminded of these events, I decided to visit the 'home' of the doctor who lost his mind; but because they had moved to another place, I could not see them that night. Instead, acquaintances introduced me to another family who had taken shelter in Antep. Though I was previously told that they were Arabs, they were a Kurdish family; the man was from Afrin and the woman from Aleppo. They lived with their children in very poor conditions in the basement of an apartment. Since I did not know them, I did not have a prepared set of topics to speak with them about. Open-ended discussions and interviews are at times shaped according to the nature of the people with whom I speak and 
their assessment of me. After I introduced myself, the man surprisingly told me that his grandfather came from a tribe in Besni in the Ottoman Empire and that once the Turkish-Syrian borders were fixed in 1921, they stayed in Syria. As I knew his tribe on a personal level, this created sympathy between me and him, and we begin to talk about historical issues. His wife also seemed content with my visit and discussion with them. The place where they lived was very small. As there was only one room, I noticed that she separated the place in two parts to create a small kitchen. She prepared tea and biscuits and served them to me. When I thanked her and asked for a second cup of tea, she was more than happy to host a guest despite their mediocre conditions. The family did not have political affiliations and felt comfortable discussing their situation with me. An occasion emerged for me to discuss an issue that I was trying to collect information on and for which I needed to speak with people who lived in northern Syria. A subethnic group called the Baggâri had been killed, likely by a Kurdish militia during the civil war in Aleppo. I had the intention of learning who they were and whether they were killed for personal or political reasons. This discussion with the family helped me complete and verify the information I had gathered about this issue, as many elements of the Syrian and Kurdish conflicts intersect.

Personal factors may shape the fieldwork in a variety of ways. Ehmedê Dirihî (Ahmet Kasımoğlu, 1949-2019) was an independent Kurdish researcher I met in Diyarbakır in 2007. He was from Palu. He worked in agricultural engineering in Turkey; he was familiar with agricultural terminology and specialised in herbs and plants. He was driven to collect Kurdish names of herbs, and visited most of the Kurdish-speaking provinces in Turkey and Iraq. It took him 14 years to meticulously compile a Kurdish dictionary (2013) in this specific domain. Despite the crucial importance of the researcher who can be both an insider of and an outsider to the group under study, being either an insider of or outsider to any community should be considered in the context of the researcher's expertise. Also, the status of an insider or outsider can be relative and fluid (Rabe 2003: 150), as it can vary depending on the race, religion, ideology, sex and language of the observer and the observed.

Another example is a study conducted by a non-Kurdish scholar, Zuhal G. Parlak, about the social structure of Samsat, which is a district of Adiyaman. Samsat, a historical village, was reconstructed after the construction of Atatürk Dam on the Euphrates, because the ancient village was submerged. Households of old Samsat, as well as several small villages, were resettled to new Samsat due to the construction of the dam. Parlak's study (2006) is a comparison of old Samsat and new Samsat through the eyes of resettled families. ${ }^{8}$ She particularly underlines language problems and the difficulty of finding a place to stay as a woman during the research process before a family could afford to accommodate her in their home. The changing and opposing representations of the researcher in the eyes of resettled inhabitants shows that perceptions can evolve during the course of research. Indeed, she had three 
different representations of herself during the fieldwork: 'savior', 'spy' and 'teacher' (Parlak 2006: 19). As habitants encountered several problems from the resettlement, they first perceived her as a 'savior': she was not from Samsat and asked questions about their problems. They believed that she was somebody who came from outside and would find solutions to their daily problems. As the fieldwork continued, and they came to realise that she could not solve any problems, they tended to perceive her as a 'spy' rather than a 'savior'. Finally, as she had worked as a schoolteacher in Samsat before her university research, and was thus already known by some locals, she established trust as a 'teacher' who worked there.

The researcher then has a meticulous research design that depends on a well-defined research question as well as practical questions that can fluctuate according to the possibilities and constraints of the fieldwork, the inclinations of the people interviewed, as well as the personality and background of the researcher. The aim is to collect material to then construct a research objective in a reflexive manner. This is a process of accumulation of facts, peoples and moments in which we try to gather information while simultaneously questioning and evaluating the data gathered.

\section{Epistemological Methodology: Classification, Categorisation and Conceptualisations}

When the researcher focuses on the accumulation of moments, peoples and facts, there is no longer just a moment, an event and a person but moments, states, beings, places and persons; all of which combined make social and historical processes. The research object relates to socialisation, becoming, organisations, nationalism, political violence or mobilisation. At this step, the researcher is not only confronted with the problems of the fieldwork but concerned in particular with the epistemology of the research, which results in the conceptual study and the making of hypotheses.

The fieldworker, when using non-guided interviews, qualitative observations or textual analyses, is supposed to construct a body of knowledge that contains themes such as violence, alienation, body, self, time, culture, identity, social class and gender. Although these themes are certainly different, they are in reality not independent or isolated from each other. Culture and society are, for example, different; however, they can refer to the same thing depending on the perspective, considering all societies contain a culture. The difference resides in abstraction from different parts of the same reality (Evans-Pritchard 1951).

Classification is a methodological step in which raw material is turned into sociological, anthropological or psychological knowledge for two reasons. First, knowledge is not really classified within society, and second, scientific conceptualisation and categorisation can break with common sense. For 
example, what society and the law calls a crime can be reconceptualised as violence. This does not mean every categorisation by society needs to be conceptualised, but rather just revised. One example is that social scientists will use the term 'honour' to study different sorts of acts, and it is a term used by the society as well. The judgement or perception of an 'honour killing' is determined by society's conception of honour. Revising this concept can usually mean using it in a critical and analytical way, because such concepts, as a researcher sees them, are not perceived in the same way by the community. Rather, they are taken for granted, because they have been internalised, and as such constitute a 'doxa' (Bourdieu 1972).

There is a significant epistemological question of what the researcher chooses to select and classify within his methodology. This will depend on the recurring topics, times and issues in the material that concern the research problem. If there is a large gap between the material and the research question, there is either a problem in the methodology or the research question is not relevant. In that case, the researcher is supposed to change the method or the central question.

A good example of an empirical study, pertinent when dealing with several analytical categories and concepts, is women's participation in the Kurdish movement. Gender is conceived as power relations between men and women and often constitutes the central concept in research objects. This is, however, too limited because social processes happen at the intersection of politics, society and culture. In examining female participation in political violence, one may notice empirical findings on social class, ethnic, generational and geographical factors likely to influence women's choices. For example, which social class does the woman come from? When and where did she join the Kurdish movement? How does she perceive oppression? Does this relate to patriarchy, ethnicity or Kurdish ideology? These sorts of questions enable the categorisation and contextualisation of knowledge before elaborating arguments about the use of violence by woman. Only afterwards is it possible to study how these different dynamics in female experience intersect with each other with the consequence of political violence (Orhan 2019).

\section{Methodology of Theoretical Issues: Inductive versus Deductive Research, the Disconnection between Empirical Evidence and Theoretical Conceptions, and the Orientalist Bias}

Theory is a tool used to make knowledge intelligible and to articulate the different categorisations and conceptualisations. In social sciences, the term 'theory' is not used in the same sense as in the natural and physical sciences (Evans-Pritchard 1951). A theory, or our research idea, is not like a physical law that shows the similar relationships between causes and effects under the same conditions. In pure knowledge, when we collect information 
in fieldwork, there is no such a law (Weber 1949). Take the example of the dynamic relationship between political violence and Kurdish mobilisation (Orhan 2015): instead of establishing static theoretical laws to show the role of political violence that mobilises or demobilises people, we must explain varying relationships between political violence and Kurdish mobilisation by asking, for example, the following questions: when, why, how, where and who mobilised whom?

There is a particular problem that occurs when theorising research: the question of using inductive or deductive methods to explain the facts. Many methodological guides discuss this and imply that researchers either have a theory that they then test, or alternatively they conduct observations and develop a theory via observation. While this is a reasonable way to distinguish induction and deduction, it is simplistic. Drawing such sharp boundaries between the two methods can be inconvenient for this distinction, as it can lead to theory being perceived as fixed rather than fluid. One cannot determine in absolute how to construct a theory, whether in the beginning or after observation; theory must remain flexible, as it is subject to change according to the data collected. A study is inductive when the starting point is the fieldwork, and deductive when theory is the starting point. It is important to keep in mind that testing and constructing a theory are inseparable procedures. In most cases, an inductive approach and a methodology work together (Gray 2004: 7), although the research is generally more oriented by theory or fieldwork findings in the beginning stages. For this reason, the researcher can formulate his method as more inductive than deductive rather than completely inductive or deductive.

There are more practical problems regarding the theorisation of a study, namely, the problem of disconnection between fieldwork knowledge and theory. This problem can result from the use of an irrelevant or insufficient theory. For example, it might be difficult to explain suicide attacks through an account of hunger strikes in the Kurdish conflict. Though hunger strikes and suicide attacks are both self-inflicted violence, they differ from each other greatly: a hunger strike is an act of protest that can even include democratic claims and peace efforts, while a suicide attack is an act of war because it kills not only oneself but other people as well (Orhan 2015). The solution is to question the pertinence of social, cultural, and political theories that we apply in the study. This questioning enables the researcher to discard or apply it with a critical approach rather than randomly selecting it.

Another reason for this disconnection is the neglect of empirical evidence. We are naturally interested in collective concepts such as state, society, culture, social class; however, these concepts in our research might be alternatively constructed through the experiences of concrete individuals, groups and places. When theory or an argument are disconnected from real individuals, groups and places, they do not offer a different perspective or an alternative approach from previous studies undertaken in a different society, context or 
culture. This is a major problem in Kurdish and Middle Eastern studies, for example, when scholars use social movement theories. Concepts and theories are being used without critical elaboration within the limits of knowledge they collect. This problem is, of course, not just a theoretical problem; it comes from the lack of a rigorous methodology and knowledge that can be applied to the theory. If one does not know a town, a village, people, its local actors, history, economic structures, it will not be possible to connect a theory with rich empirical evidence. In spite of resolving this problem, a certain tension can still exist between evidence and theory, because while they are both elements of scientific knowledge, they do not have the same nature. Tension between evidence and theory is not like the opposition between fiction and reality. A theory is derived from evidence and explains social facts. Fiction, on the contrary, is an artificial production that is not necessarily related to reality.

The same sort of problems occurs when dealing with the choice of concepts that orient us when applying the theory. The key concepts are to be analytical; however, the researcher can use some peripheral concepts in a descriptive manner without elaborating all of the terms in the same manner and degree. For example, if social movement theory is used to study a question in Kurdish society or politics, the concept of framing can be a key analytical term in explaining why people join a movement. It is, however, a mistake to apply these kinds of concepts in a non-critical manner to Kurdish or Middle Eastern studies. A critical perspective is necessary given that such concepts are constructed through the study of Western social movements that largely lack traumatic experiences. The question of why we are using a specific concept is a crucial question, as is the relevance of field observations to the overall theory, and the link between the concept and theory (in this case, explaining participation with the concept of framing). A critical approach to existing theories is based on knowledge, and criticism contributes to the development of knowledge (Lakatos and Musgrave 1970).

Similarly, when applying a theory of nationalism and ethnicity, a historian may need to consider a number of questions. Is it, for example, pertinent to define Kurdish movements in the nineteenth century as nationalist movements? Indeed, framing these movements as nationalistic in this historical period is an anachronistic view. Actors involved in these movements were not politically motivated by nationalism, though they were opposed to the centralisation of the Ottoman state authority. As such, what concepts can be used in this situation? How important is it that scientific categories explain with practical correctness the actions of the actors concerned? In this respect, the social scientist must examine individual and collective consciousness as determined by objective factors like tribalism, Kurdishness, fathership, malehood, mothership, childhood, womanhood, pain and their subjective formulations, such as 'My tribe is the enemy of ...', 'Kurds are a nation to be woken up', 'Women are oppressed because .... As Theodore Schwartz and Margaret Mead (1961: 3) said, 'Each individual derives implicit cognitive-affective-evaluative 
constructs from his participation in the events that make up his life history.' When concepts are irrelevant, and do not explain actions, behaviors or cultural and socioeconomic conditions, the researcher faces the same problem of disconnection between theory and evidence.

Kurdish studies are sometimes confronted with a specific bias resulting from orientalist perspectives, policy-oriented pieces, or journalism. It is important to have a critical perspective regarding these approaches, because 'knowledge is produced in certain people's interests' (Tickner 2001: 33). Though these approaches have no particular theory, they can induce biased constructions and representations regarding historical and contemporary problems in the Middle East. To take the definition by Edward Said ([1978] 2003), orientalism is an approach that constructs the Orient in accordance to one's own stereotypes and interests and fantasies, in relation to the power relations within that specific context. Orientalism led to a fantasised narrative when writing about the Kurds during the twentieth century. The problem in this case is that theoretical and historical explanations can be affected by biased arguments. Orientalist perspectives depicted Sheikh Said as a man who manipulated the religious feelings of poorer Kurds in order to motivate them to revolt against the Turkish Republic in 1925. This explanation assumes that they were misled by the sheikh, or that Khoybun was the principal force behind the Kurdish rebellions after Sheikh Said's uprising. On the contrary, Sheikh Said shared the same ideas and sentiments as his followers (Orhan 2012) regarding the protection of the caliph, and the rebellion developed as a result of this convergence of the upper and lower classes against the emerging nature of secular Kemalism. As for the case of Khoybun, it was a modern political organisation founded in French Mandate Lebanon during the 1920s that aimed at regrouping the Kurds. This ambition does not suffice to claim that it succeeded, because the organisation was composed only of exiled elites entirely disconnected from the masses due to remote conditions, their modernist lifestyles and the fact that most of the Kurds were not even aware of them (Orhan 2012). The orientalist bias regarding Sheikh Said's rebellion is due to the misinterpretation or disregard of the religious factor in Sheikh Said's rebellion, and the bias concerning Khoybun is due to the exaggeration of the role of this political organisation in Kurdish history and society.

The term 'orientalist' is, however, sometimes used as a vulgarised way to evaluate a work without considering why and what content is orientalist within a work. For example, despite having questionable arguments, Basile Nikitine (1956) made an exceptional contribution to Kurdish studies through his book, which was both a comprehensive and in-depth study on the Kurds based on long-term fieldwork. Nikitine formulated many of the key ideas regarding historical and social questions such as nationalism, religion, tribe, language and tradition, at least in descriptive ways that inspired many scholars since then. His book has an outstanding ethnographic value, and methodological and theoretical rigor about social and cultural structures, and as such it is 
comparable to classic works in anthropology like those by James G. Frazer (1908), Bronislaw Malinowski (1932) and E.E. Evans Pritchard (1951). In spite of the merits of his work, Nikitine is not sufficiently cited either in Kurdish studies or social sciences. This is likely due to the fact that he was a Soviet orientalist rather than a Western one, showing the clear hierarchy among orientalist schools of thought. In addition to the content of a given text, an author's name or place of origin unfortunately seem to dictate the reception and valorisation of his or her work in the scientific field (Foucault 1969: 34).

A reasonable question to ask is whether orientalism in Kurdish studies differs from orientalist approaches to other Middle Eastern cultures, politics and societies. While orientalism has common characteristics, as defined by Edward Said ([1978] 2003), the approach produces topic- or context-specific biases. Islamic and female issues in particular are subject to more orientalist approaches, whether they are being discussed in the context of Kurds, Syrians, Pakistanis or Iranians. For example, it is an instance of orientalism or ethnocentrism to define an Alevi dede or $p \hat{i} \hat{r}^{9}$ or a Sunni sheikh, imam or âlim (Muslim scholar) as a cleric or within the framework of clericalism, whether they are Kurdish, Turkish or Arabic, because the clergy is a religious authority specific to Christianity. In general, Middle Eastern studies from an orientalist approach produces different terminologies and representations, such as 'moderation' or 'fundamentalism', to study conflict and violence. While real facts, they are framed through biased ideas from which Kurdish studies are not immune. ${ }^{10}$

Another example, this time dealing with gender issues, is Kurdish female fighters' representation in the Western media (Baser and Toivanen 2016). This is a pertinent illustration of media orientalism, and there are two apparent reasons for this bias. First is the will to represent the Kurdish struggle within the conflict framework of civilisation versus barbarians in the Syrian civil war (Baser and Toivanen 2016). ${ }^{11}$ This neglects to account for political issues surrounding Kurdish identity, territory and language. Second is the instrumental use of women to represent this stereotyped framework by the media. Such an example also shows how orientalism is not limited to classical Kurdish studies but can be reproduced under contemporary conditions. Kurds are portrayed in the media and the academia through Western systems of representation. Kurdish politics and society are studied within the framework of security, or orientalist and imperial interests. Therefore, the way in which the global order includes and excludes the Kurds from the international system is questionable, as it fails to consider the Kurds as they are. As such, the challenge any scholar faces in Kurdish studies is not just the difficulty of conducting fieldwork, but also the biased ontology, historiography and epistemology resulting from conventional studies in the West or the East.

The reason why biased arguments remain influential is an intellectual conformism that exists in all area of social sciences, media and politics. These fields are places of power relations that orient people towards particular modes 
of thinking and acting. Orientalism is certainly not the sole reason for this conformist bias. The Middle Eastern states where the Kurds live produce official state discourses, consequently influencing scholars in the construction of their arguments (Beşikçi 1991). As Mesut Yeğen (1999) studied, the state discourse, particularly in Turkey, has long framed the Kurdish problem as merely tribal, foreign provocation and underdevelopment. Turkish historiographical discourse has long rested on the authority of Western orientalism (Copeaux 1997: 72-73, cited by Scalbert-Yücel and Le Ray 2006), especially viewing political and social questions through the progression and backwardness dichotomy. Orientalist, media, imperial or national state narratives influence and converge with each other, affecting a wide range of scholars and creating different sorts of biases. As researchers are located within power relations, the orientalist bias and state narratives are not a mere question of intellectual influence from accumulated knowledge, but of power relations and selfish interests depending on who is positioned according to what and whom in the scientific field. Any orientalist 'prominent professor' will encourage his followers as 'promising' scholars, which is the result of hegemonic relations between the 'prominent' and the 'promising. A biased argument can influence both insider and outsider researchers, creating the need for a serious re-evaluation of the argument's value. To have a critical thesis on Kurdish studies, it is more important to question in whose interests any bias is produced, whether it is 'anti-Kurdish' or 'pro-Kurdish'. Most methodological research focuses on power inequalities between the observer and the observed, without combining this problem with power relations between the observer and the national or world politics. Thus, there are two conclusions perhaps equally important: the role, speech and interests of the researcher are influenced by power relations. Furthermore, once imperial orientalism and national chauvinisms structure their epistemes, namely, the whole of ideas and commonsense understandings, they determine the creation and perception of knowledge in Kurdish studies that shape the representation of the Kurds within the society, media and universities.

\section{Conclusion}

Method is the way in which one conducts research and constructs a research object. It includes 'the specification of the steps' (Watzlawick et al. 1974: 7) in a particular investigation. Methodology refers to 'the study of the plurality of methods' (ibid.: 8). It is divided into three interrelated categories, fieldwork methodology, methodology of the epistemology and methodology of theory. By dealing with methodology on three levels, this text has discussed various experiences, insights and problems that occur when undertaking research on the Kurds.

First, there is a specific challenge (topicism) found in area studies, like Middle Eastern studies, if the research is only defined by a topic, society 
or geography and ignores social, cultural or political problems. Questionoriented research rather than topic-oriented research will enable a better formulation of a scientific problem (Eidlin 2011; Evans-Pritchard 1951; Katz 2001). An extensive and in-depth knowledge of the entire society and how its internal dynamics, such as culture and politics, intersect is needed to handle specific social questions. Ethnographic processes, like interviews, include their key tools, ways and specific questions that enable collecting the material. This material can include information about different sorts of events, places and people. Once the material is collected, it is selected, classified, categorised and conceptualised according to certain research principles. The research then moves from the obtaining knowledge stage to the problem of knowledge interpretation. At this point, the researcher can face various challenges regarding theory and evidence. Good research is the synthesis of empirical evidence with theory. As these challenges are relevant to all social and political science research, Kurdish studies do not fundamentally differ from that of other groups when it comes to theoretical issues. Like the study of any population: it is the study of human beings. Thus, it is not beneficial to isolate Kurdish studies from Middle Eastern studies as a whole, or social sciences, when discussing operational definitions and methodological hypotheses.

Second, this is, however, not to say that the way we observe and what we observe about the Kurds is identical with other observations and theses. Indeed, every interview, ethnography and observation is unique when taking its historical, existential and subjective senses into account. The specific way in which people express themselves, embedded in a particular place, time, history and culture (Hall 1990: 222), interacts with the background, knowledge and personality of the researcher. This combination shapes interactional patterns influencing the way one conducts research. Subsequently, epistemologies and hypotheses derived from each research are unique as well.

Third, in addition to these personal factors contingent upon the characteristics of the researcher, there is a factor that makes Kurdish studies special: its political significance. One hundred years ago, the context was the dissolution of the Ottoman Empire and the emergence of the new nations and states that experienced Kurdish conflict in various forms since then. This makes the Kurdish context permanently political. Whether the researcher intends to be political or not, his or her conditions are, and so the research may have political and ethical implications. Furthermore, the increasing political importance and radicalisation of the Kurdish conflict lead to particular challenges around the access to empirical data and the objectivity needed when dealing with such political questions. The method of the research (including place, time and questions) is increasingly shaped by war, the Kurdish conflict and populations' displacements. Faced with these types of challenges, the difficulty in collecting primary materials becomes a major methodological issue. Apart from this challenge, it is important to have a critical approach because the Kurds are often observed through an orientalist lens or official state discourses, which 
produce conformist biases because they depend on power relations in the scientific field, media or any field that constructs ideas, arguments and representations of the social, cultural and political world.

Mehmet Orhan is a researcher in the social and political sciences at the UCLouvain in Belgium. He studied French, English and Turkish translation at Bilkent University (Bachelor of Arts), Arabic language, literature and civilisation at Paris Sorbonne Nouvelle 3 (Bachelor of Arts), political science at Sciences Po Paris (Master of Arts) and sociology at EHESS (Master of Arts and $\mathrm{PhD}$ ). Email: mehmet.orhan@uclouvain.be.

\section{Notes}

1. The cultural unity of a population can be fictive and variable depending on the aspects of culture we question. Despite limitations and internal differences, Kurds have preserved a relative cultural unity that is not political. Cultural unity, in this case, is not homogeneity, social solidarity or a collective sense of belonging to a nation; rather, it refers to some common customs (e.g., table manners), tradition, songs, kinship patterns, etc. If an ethnic population does not maintain a minimum set of shared cultural patterns, it ceases to be a distinct community.

2. The term 'elite' does not only refer to economic wealth, social class or status but also includes social capital, influence and power within the society and culture in question.

3. For more information, see Gunter (2014), Vali (2014) and Aziz (2015).

4. If it is constructed before preliminary observation, the research question can be revised, reconstructed or reformulated after the initial observations. It is ideal if the empirical observations can prove the relevance of the research question, but it is of course possible to change the research problem or reformulate it if one finds facts that do not confirm the initial hypothesis prior to the fieldwork.

5. This approach was constructed by Fernand Braudel (1958) with the purpose of focusing on interrelated economic patterns, social events and cultural phenomena as well as their changes and continuities over long periods of time.

6. The Seyyid (or Sayyid) are people who are believed to be descendants of the Prophet of Islam.

7. Kobanî is a Kurdish town in northern Syria where most districts were occupied by ISIL for a few months in 2014.

8. Although Parlak recognises Kurdish ethnic characteristics of Samsat, she avoids speaking much on this issue in her descriptions and analyses.

9. To provide dictionary meanings, dede is 'grandfather' in Turkish and pîr is 'old man' in Kurdish and Farsi. A dede or pîr is a religious authority who governs cem, a principal ritual in Alevism. 
10. Although outside the scope of this article, orientalism is not only specific to Muslim societies. Assyrian and Armenian populations are also often represented in an orientalist manner even in terms of their historical and contemporary relationships with Kurds, regardless of whether these relationships were/are peaceful or violent.

11. Baser and Toivanen (2016) handle this issue in a very conformist manner, as they are merely content to suggest that the representation is gendered without asking why it is so.

\section{References}

Atkinson, P., Coffey, A., Delamont, S., Lofland, J. and Lofland, L. (2001), 'Editors' Introduction', in Handbook of Ethnography, (ed.) P. Atkinson, A. Coffey, S. Delamont, J. Lofland and L. Lofland, (London: Sage), 1-8.

Aziz, M.A. (2015), The Kurds of Iraq: Nationalism and Identity in Iraqi Kurdistan (London: Palgrave Macmillan).

Baser, B. and Toivanen, M. (2016), 'Gender in the Representations of an Armed Conflict: Female Kurdish Combatants in French and British Media', Middle East Journal of Culture and Communication 9, no. 3: 294-314.

Beşikçi, İ. (1991), Bilim-resmi ideoloji devlet-demokrasi ve Kürt sorunu (Ankara: Yurt Yayın). Bidlîsî, Sharaf Khân [1597] (1969), Chèref-nâmeh (trans. from Persian and with comments by François Bernard Charmoy) (Westmead, UK: Gregg International).

Bourdieu, P. (1972), Esquisse d'une théorie de la pratique: Précédé de trois études d'ethnologie de Kabyle (Geneva: Editions Droz).

Braudel, F. (1958), 'Histoire et sciences sociales: La longue durée', Annales 13, no. 4: $725-753$.

Copeaux, E. (1997), Espaces et temps de la nation turque: Analyse d'une historiographie nationaliste, 1931-1993 (Paris: CNRS Editions).

Crenshaw, K. (1991), 'Mapping the Margins: Intersectionality, Identity Politics, and Violence against Women of Color', Stanford Law Review 43, no. 6: 1241-1299.

Edwards, R. and Holland, J. (2013), What Is Qualitative Interviewing? (London: Bloomsbury).

Eidlin, F. (2011), 'The Method of Problems versus the Method of Topics', Political Science and Politics 44, no. 2: 758-761.

Evans-Pritchard, E.E. (1951), Social Anthropology (London: Cohen \& West).

Frazer, J.G. (1908), The Scope of Social Anthropology (London: MacMillan).

Foucault, M. (1969), L'archéologie du savoir (Paris: Gallimard).

Freud, S. (1920), A General Introduction to Psychoanalysis (New York: Horace Liveright).

Gellner, E. (1984), Nations and Nationalism (Oxford: Basil Blackwell).

Gezik, E. (2013), 'Rayberler, pirler ve murşidler (Alevi ocak örgütlenmesine dair saptamalar ve sorular)', in Alevi ocakları ve örgütlenmeleri, (ed.) Erdal Gezik and Mesut Özcan, (Ankara: Kalan Yayınlar1), 11-77.

Gray, D.E. (2004), Doing Research in the Real World (London: Sage Publications).

Gunter, M.M. (2014), Out of Nowhere: The Kurds of Syria in Peace and War (London: Oxford University Press). 
Hall, S. (1990), 'Cultural Identity and Diaspora', in Identity: Community, Culture, Difference, (ed.) Jonathan Rutherford, (London: Lawrence \& Wishart), 222-237.

Hegland, M.E. and Friedl, E. (2004), 'Ethnographic Fieldwork in Iran', Iranian Studies 37, no. 4: 569-573.

Hudson, B.A. and Okhuysen, G.A. (2014), 'Taboo Topics: Structural Barriers to the Study of Organizational Stigma', Journal of Management Inquiry 23, no. 3: 242-253.

Kasımoğlu, A. [Dirihî, E.] (2013) Ferhanga navên nebatan a Kurdî (Mardin: Mardin Artuklu Universitesi).

Katz, J. (2001), 'From How to Why: On Luminous Description and Causal Inference in Ethnography (Part I)', Ethnography 2, no. 4: 443-473.

Laing, R.D. (1969), La politique de l'expérience (Paris: Editions Stock).

Lakatos, I. and Musgrave, A. (1970), Criticism and the Growth of Knowledge (Cambridge: Cambridge University Press).

Lazarsfeld, P.F. and Oberschall, A.R. (1965), 'Max Weber and Empirical Social Research', American Sociological Review 30, no. 2: 185-199.

Malinowski, B. (1932), Arganouts of the Western Pacific (London: Routledge).

Nikitine, B. (1956), Les Kurdes: Etude sociologique et historique (Paris: Imprimerie Nationale, C. Klincksieck).

Orhan, M. (2012), 'Kurdish Rebellions and Conflict Groups in Turkey during the 1920s and 1930s', Journal of Muslim Minority Affairs 32, no. 3: 339-358.

Orhan, M. (2015), Political Violence and Kurds in Turkey: Fragmentations, Mobilizations, Participations and Repertoires (London: Routledge).

Orhan, M. (2019), 'The Intersectional Dynamics of Political Violence and Gender in the Kurdish Conflict', Studies in Ethnicity and Nationalism 19, no. 3: 269-288.

Parlak, Z.G. (2006), Suya batan güneş: Samsat (Ankara: Turhan).

Rabe, M. (2003), 'Revisiting "Insiders" and "Outsiders" as Social Researchers', African Sociological Review 7, no. 2: 149-161.

Said, E.W. [1978] (2003), Orientalism (London: Penguin).

Scalbert-Yücel, C. and Le Ray, M. (2006), 'Power, Ideology, Knowledge: Deconstructing Kurdish Studies', European Journal of Turkish Studies, no. 5, http://journals.openedition. org/ejts/777.

Schwartz, T. and Mead, M. (1961), 'Micro- and Macro-Cultural Models for Cultural Evolution', Anthropological Linguistics 3, no. 1: 1-7.

Skocpol, T. (1994), Social Revolutions in the Modern World (Cambridge: Cambridge University Press).

Tickner, A.J. (2001), Gendering World Politics (New York: Columbia University Press). Vali, A. (2014), Kurds and the State in Iran: The Making of Kurdish Identity (London: Tauris).

Vanl1, İ.Ş. (1968) Le problème kurde en Syrie (n.p.: Comité pour la défense des Droits du Peuple Kurde).

Watzlawick, P., Weakland, J.H. and Fisch, R. (1974), Change: Principles of Problem Formation and Problem Resolution (New York: Norton).

Weber, M. (1949), The Methodology of the Social Sciences, (ed.) Edward A. Shils and Henry A. Finch (Glencoe: Free Press).

Weber, M. (1971), Economie et société, 2 vols. (Paris: Plon).

Yeğen, M. (1999), Devlet söyleminde Kürt sorunu (Istanbul: İletişim). 